ON SOME POINTS OF

\title{
THE PATHOLOGY OF YELLOW FEVER.
}

\author{
BY \\ CROKER PENNELL, M.B., LOND., \\ MEMBER OF THE ROYAL COLLEGE OF SURGEONS; FORMERLY \\ LECTURER ON ANATOMY AND PHYSIOLOGY AT WESTMINSTER HOSPITAL; \\ Physician to THE LIVRAMENTO hospital, RIO DE JANEIRo.
}

COMMUNICATED BY

DR. GULL.

Received February 7th.-Read February 22d, 1853.

I feel that some apology is due for introducing a subject that has given rise to such fierce and unbecoming controversy as yellow fever; but an intention to avoid what have really become party questions, and a hope of being able to supply some facts of practical value, have induced me to offer for consideration and discussion the following observations, which, I believe, will be found to describe some pathological considerations of considerable importance that, as far as I can ascertain, have hitherto been overlooked, or referred to in a manner from which it is manifest their value was not recognised.

Of all diseases, yellow fever is perhaps the most insidious. It frequently happens that patients who have been pronounced convalescent, or free from danger, by practitioners of great experience and observation, have suddenly and unexpectedly expired, without leaving any post-mortem appearances by which the physician could explain the event, 
or derive indications by which his prognosis might, in future cases, be more correctly formed; e. $g$., a patient has passed through one or two violent accessions of fever, which have subsided, and return no more. He expresses himself much relieved, or perhaps feeling quite well; the tongue is clean; the pulse 70, round and soft; the skin cool, intelligence perfect, and the secretion of urine apparently natural. Notwithstanding all these favorable indications he suddenly expires.

Cases, such as the one I have related by way of illustration, occasionally occurring in my own practice, perplexed me considerably. Theorising upon the subject with the view of discovering some plausible explanation of the phenomena in question, it appeared to me unlikely that any diseased condition of the solids (fatty heart excepted, being inapplicable to the present case,) could so suddenly produce death without having previously afforded some indication of its existence, and therefore that the cause of death would be found in the blood or its circulation. Bearing in mind the extreme congestion of the capillaries of the skin (usually existing in this class of cases), I imagined that the capillary system of all the organs and tissues of the body was in a similar state, and that the congestion suddenly increasing (from many causes which may be readily supposed) was in itself sufficient to bring the circulation to a stop, and thus to cause sudden death.

While in this state of uncertainty, I accepted the appointment of physician to an hospital, where I became the colleague of Dr. Lacaille, a French physician. In conversation he stated to me his conviction that, in the cases referred to, death was caused by the formation of fibrinous clots either in the cavities of the heart or in the large vessels leading to them. He had records of two hundred post-mortem examinations, made upon individuals who had died of yellow fever, and in no instance, where death had suddenly occurred, was the clot absent. The observation, however, derives its greatest importance from the fact that the clot is to be found either in the heart or large veins, in every case of 
death by yellow fever, where depletion has not been largely practised.

I became attached to the hospital referred to at Rio de Janeiro in February, 1852, and between that month and the end of May, I made upwards of fifty post-mortem examinations of individuals who had died of yellow fever, and whose cases I had observed during life. A clot was found in every instance, with the exception of those cases which had been largely blooded, and even these did not always form an exception.

It will, I have no doubt, be urged that the state I have described is a dying or post-mortem one. A sufficient refutation of this opinion is the fact that it can be diagnosed during life, two, three, or four days before death, and as early, sometimes, as the close of the second day of disease, while the system is still vigorous, the fever acute, and the functions of life, though greatly disturbed, are performed in full activity.

Sometimes no symptoms exist to denote the mischief that is going on ; but generally there is great distress or fatigue in the breathing, and an indescribable anxiety is felt at the præcordia or under the sternum. Upon auscultation, the heart, in an early stage, is generally found to be beating violently, but communicates very little impulse to the ribs, suggesting the idea of a small distant heart impetuously acting. The pulse, though at first not much affected, soon becomes contracted, small, and soft, affording a remarkable contrast to the forcibly acting heart; occasionally, however, it retains its volume, notwithstanding the existence of the clot, a peculiarity depending probably upon the position of the latter. The sounds of the heart's action are either very much subdued, or one or both are entirely lost. When the formation of the clot takes place very rapidly, a species of rumbling or churning sound accompanies the disappearing of the natural sounds. Both sounds become less distinct as the disease progresses, but I cannot assert that either one is always and regularly lost before the other. In some instances the first, and in others the second, seemed to be that which 
was first affected. It is generally the second sound which is first and most seriously affected. The irregularity probably depends upon the different positions occupied by the clots. When found in the heart, the clot always exists in the right ventricle, or ventricle and auricle, but is usually accompanied by another of smaller size in the left. There may also be clots in the venæ cavæ, and sometimes, but less commonly, in these alone.

That the clot directly gives rise to the formation of a rumbling or churning sound is extremely probable; but $I$ imagine that the feebleness or loss of the natural sounds is, in some measure, owing to the obstruction the circulation experiences in the right ventricle, whereby but little blood passes through the lungs to the left side. Hence, also, the pain, or rather the distressing and indescribable anxiety felt at the præcordia or under the sternum, and the catching or sighing respiration.

These surmises require further observations to confirm.

The clot sometimes almost entirely fills up the cavity of the ventricle, or of the vessels in which it is found, and would, if existing during life, be quite sufficient to obstruct the circulation to an extent that would prove suddenly fatal, and that would satisfactorily account for the loss of the heart's sound, both by a want of circulating fluid and by the clot mechanically interfering with the movements of the heart's valves.

The clot is generally more or less round, of a clear bright amber colour, of a gelatinous appearance, but, upon closer examination, is found to be much tougher, and evidently fibrinous. By preservation in spirits it becomes opaque, of a dirty grey colour, and shrinks somewhat; sometimes the surface or the extremities of the clot have small portions of coagulated blood adhering to them. For other peculiarities I refer to the preparation now exhibited. It was taken within one hour of the patient's death, - a lapse of time that would hardly suffice, as a post-mortem phenomenon, for the formation of such large and perfectly bloodless clots, found both in the ventricles and in the large 
blood-vessels. Upon examining the right ventricle of the preparation exhibited, it will be seen that the fibrinous mass interlaces itself with the carneæ columnæ and chordæ tendineæ, tying them, and evidently interfering considerably with their movements, and perhaps so far affecting the action of the valves as to co-operate with other causes in diminishing the intensity of the natural sounds. I have not discovered any abnormal bruit in these cases, further than the churning sound already referred to. The clots in the ventricles are so much smaller than those which are frequently met with, that a very imperfect idea will be formed of the extent to which they are capable of obstructing the circulation, always supposing that they existed during life. The chief value of the observations just made depends upon substantiating this fact. The following considerations convince me of its truth :

1st. I have found them as bloodless and as perfect within an hour of death as at any subsequent period at which an examination may have been made.

2d. I have diagnosed their existence several days before death in nearly a hundred instances, all of which, as I predicted, proved fatal. In upwards of fifty of these cases I verified, by post-mortem examination, the absolute presence of the clots; the remaining cases were not examined. I admit that the evidence is not conclusive; but its value is considerably enhanced by the fact that I have never diagnosed the presence of a clot in a case that recovered; so that, be the explanation what it may, an examination of the condition of the heart has given me a clearness and certainty of prognosis, in a most insidious disease, which I did not before possess. It is hardly possible that the result should be purely accidental. During the three months that my attention was particularly directed to the state of the heart in yellow fever, $I$ attended upwards of three hundred cases, and the result verified in every instance a diagnosis, founded upon an examination of the condition of the circulatory apparatus.

It occasionally happened that the signs which I have 
mentioned as indicating the presence of clots in the heart were so obscure that no diagnosis could be confidently formed; and in these cases it was necessary to suspend the judgment until the disease was further developed, or to form a diagnosis from other sources of evidence.

It is true that the clots do not possess such a clearly laminated appearance as would indicate their slow formation; and it thus becomes a question whether it be compatible with our ideas of the formation of clots from diseased blood, that those described should take place during life; and, secondly, whether these ideas are sufficiently precise and irrefragable to outweigh the evidence which I can adduce in support of the opposite view.

3d. I have found fibrinous clots in other organs, as will be presently mentioned, that must necessarily have been formed during life.

4th. The supposition that a clot exists in the heart, will frequently explain events that are otherwise inexplicable.

The only counter-argument that appears to me of much weight, is the fact of the clots not possessing distinct laminæ, from which it may be inferred that their formation was not progressive or during life. It should, however, be remembered, that I am describing a change which takes place in a highly-diseased condition of the blood; and I feel pretty sure that I have seen fibrinous exudations, the result of inflammation in broken-down strumous constitutions, with no better traces of laminæ than the clots now presented for examination.

It has been mentioned that clots have been found in other organs besides the heart and large blood-vessels. The allusion related to fibrinous exudations, or distinct clots, which upon two occasions $I$ found in the ureters of individuals who died of yellow fever. Although I can only mention two instances in which I observed the occurrence, I have no doubt that it frequently happens in a smaller degree. In those referred to, the ureters were so completely blocked up by the masses, that it was sufficient to obstruct in toto the flow of urine. The fibrinous exudations 
more generally occur in the tubuli uriniferi; at least, I think as much may be justly inferred from what $I$ am about to relate.

Suppression of urine is not uncommon in severe cases of yellow fever, and it is almost invariably fatal. Out of many hundreds, I can recollect but one instance (in which it was ascertained by the catheter, that suppression of urine existed and continued for twenty-four hours, that the patient recovered. This man was bled largely three times in twentyfour hours, and made a good recovery. Suppression occurred early in the disease, and was treated by active venesection.

I very much regret that the investigations which I made upon the diseased conditions of the kidneys and of the urine in yellow fever do not possess that precision which the subject admits of. I am no analytical chemist, and practically unacquainted with the use of the microscope. I have been obliged to dispense with the assistance to be derived from these two branches of science, very important, I confess, in the present inquiry. I must, therefore, content myself with relating faithfully the changes and abnormal appearances observed by the unaided senses; and I hope that although my observations may be meager, compared with the richness of the subject, they will suffice to show the importance of conditions hitherto, I believe; unknown, and also to impart, as far as the observations extend, some definite and practical information upon the subject discussed.

It will not be expected that in a disease of such varying intensity as yellow fever, there should be a perfect uniformity of symptoms. During an epidemic, many individuals pass through a mild species of fever; that after a single paroxysm which has not confined the patient to bed, returns no more. Between this and the most intense form every variation of degree is met with. It is important, however, to remember that a fever, which during the first two or three days appeared to be of the mildest possible kind, occasionally assumes suddenly the worst features of the disease, and runs a rapidly fatal course. 
It rarely happens that a patient suffering from yellow fever does not pass albuminous urine. In the slightest cases, the albumen may be, and generally is, so small in quantity, as to be scarcely discernible; but in every instance where the fever is well marked, the presence of albumen may be readily detected. In some instances I have known the urine, when heated, to become an entire solid mass.

In cases which at the beginning appeared to be mild, but afterwards proved fatal, I have derived considerable assistance in forming my prognosis by an examination of the urine, the quantity of albumen being altogether disproportionate to the apparent severity of the attack.

When the urine is scanty, the fluid passed through the kidneys appears like turbid serum, with small particles, apparently of lymph, floating through it, the whole being very coagulable. It has neither urinous nor aromatic odour, and I presume that, if analysed, it would be found deficient in urinous principles, and probably without any urea. This condition of urine is, I believe, as certainly fatal as total suppression, appearing more like an exudation of serum than a secretion of urine. If it be scanty and coagulable, but of a urinous character, the patient may escape.

In cases of turbid serous-like urine, and also of a scanty or suppressed urine, I cannot but think that the tubuli uriniferi are partially or entirely blocked up by exudation matter. The fluid which escapes evidently contains exudation matter in abundance; and this would account most satisfactorily for the scanty or suppressed secretion. The kidneys when examined are found congested, and the papillæ yield upon pressure a glutinous tenacious exudation, sufficient, I believe, to interfere mechanically with the escape of urine. Whatever may be the explanation, this remarkable condition of the urine is very important in a disease where suppression is so common that, in the Rio de Janeiro epidemics, about eighty out of every hundred fatal cases are attended by this symptom.

Although all may not concur in the conclusions I have 
arrived at, especially that referring to the formation of clots in the cavities of the heart during life, it will receive general assent, that the points discussed possess considerable value, as they at least afford evidence of the diseased state of the blood, and of the great disposition in yellow fever to the throwing out of albuminous or fibrinous matters, owing probably to their excess.

Blood drawn in yellow fever is generally very dark coloured, and sometimes almost black; but when the circulation is more than usually rapid, it may retain its bright red colour. It may be considered a very bad indication when the colour of the blood does not brighten under the effects of bleeding. The appearances of the blood drawn vary considerably; sometimes it remains very black and carbonaceous looking, with little separation of the serum; it may brighten by exposure to the air, and form a tolerably healthy-looking clot; it often throws out a thick buffy coat, the fibrin of which is seldom firm, and is sometimes so soft as to resemble a thick mass of size on the top of the clot. I have in such cases seen the fibrinous matter nearly as thick as the rest of the clot, and so gelatinous in appearance as to afford some explanation of the reason why the clots formed in the heart and large blood-vessels are not more distinctly laminated.

Without presuming to offer a theory to explain fully the nature of a disease which even now finds advocates, who complacently solve the question by a reference to contagion, I may suggest the necessity of examining the condition of the blood, in order to discover the first evidence of disease. 